\title{
The Effects of Magnetic Dopant on the Structural and Electrical Properties in Superconducting $\mathrm{YBaCu}_{3} \mathrm{O}_{7-\delta}$ Ceramic
}

\author{
Souheila Chamekh*, Abderrahmane Bouabellou \\ Thin Films and Interfaces Laboratory, University of Constantine, Constantine, Algeria \\ Email: *chamekhsouheila@yahoo.fr
}

How to cite this paper: Chamekh, S. and Bouabellou, A. (2018) The Effects of Magnetic Dopant on the Structural and Electrical Properties in Superconducting YBa$\mathrm{Cu}_{3} \mathrm{O}_{7-\delta}$ Ceramic. Advances in Chemical Engineering and Science, 8, 1-10. https://doi.org/10.4236/aces.2018.81001

Received: November 5, 2017

Accepted: January 28, 2018

Published: January 31, 2018

Copyright $\odot 2018$ by authors and Scientific Research Publishing Inc. This work is licensed under the Creative Commons Attribution International License (CC BY 4.0).

http://creativecommons.org/licenses/by/4.0/

\begin{abstract}
The work reported in this paper aims at a better understanding of the magnetic doping effects on the structural and electrical properties for a series of $\mathrm{YBa}_{2}\left(\mathrm{Cu}_{1-\mathrm{x}} \mathrm{Co}_{\mathrm{x}}\right)_{3} \mathrm{O}_{7-\delta}$ ceramics. The Co doped $\mathrm{YBa}_{2} \mathrm{Cu}_{3} \mathrm{O}_{7-\delta}$ are (YBCO) prepared by conventional solid state reaction method and characterized by $\mathrm{X}$-ray diffraction (XRD) and scanning electron microscopy (SEM), differential thermal analysis (DTA) and resistivity measurements. The crystal lattice parameters are found to change due to the cobalt doping and tendency to a structure phase transition from orthorhombic to tetragonal, which is confirmed by the decrease of the degree of orthorhombicity. The morphology examination with SEM revealed gradual increases of grain size with $\mathrm{x}=0.02$ Co, a high porosity is observed in the doped samples compared to the pure one. The decomposition temperature of $\mathrm{YBCO}$ is pushed from temperatures above $975^{\circ} \mathrm{C}$ to lower temperatures of $945^{\circ} \mathrm{C}$. The resistivity measurements of doped samples with $\mathrm{x}=0.04$ and 0.06 ; shows a deviation in from $T$-linear behavior due to the opening of a pseudogap.
\end{abstract}

\section{Keywords}

YBCO Doped Co, Electrical Properties, Phase Transition, High Tc Superconductivity

\section{Introduction}

High- $\mathrm{T}_{\mathrm{c}}$ superconductors (SC) cuprates remain one of the most intriguing and not completely understood systems, however, the researchers focused on the experimental side wondering to identify new phenomena in this type of material. YBCO is one of the most widely studied compounds among the high- $\mathrm{T}_{\mathrm{c}} \mathrm{SC} \mathrm{cu}-$ 
prates, due to simplicity of synthesis procedure by solid-state reaction, the easy availability of the starting powders, and the non-toxicity of the material compared to the other high-Tc superconductors such as $\mathrm{Tl}$ and $\mathrm{Hg}$ based oxides [1]. The partial substitution in the parent YBCO structure has been investigated intensively in an attempt to clarify or improve the superconducting behavior of this type of superconductors [2] [3] [4] [5] [6]. Transition metal oxide materials with perovskite-like structures have been extensively investigated in the recent decades for their novel properties such as superconductivity, ferroelectricity, and colossal magnetoresistance [7]. The $\mathrm{Cu}$ atoms in YBCO are located at two different sites in the unit cell. One of the $\mathrm{Cu}$ sites is in $\mathrm{CuO}_{4}$ in the basal plane $\mathrm{Cu}(1)$ which forms the $\mathrm{Cu}-\mathrm{O}$ chains; the other one is called $\mathrm{Cu}(2)$, in pyramids slightly displaced from the basal plane and forms $\mathrm{Cu}-\mathrm{O}$ planes. The $\mathrm{CuO}_{2}$ plane is sometimes referred to as the superconducting plane: Any modification in this plane strongly influences the electronic structure and the density and mobility of the charge carriers. On the other hand, the substitution at the $\mathrm{Cu}(1)$ chain site leads to the localization of carriers and weakening of the $\mathrm{Cu}-\mathrm{O}$ chains as carrier reservoir. As a result, the hole carriers cannot easily transfer to the $\mathrm{CuO}_{2}$ planes. The pairing and transportation of carriers are thus affected indirectly, and the superconductivity gets suppressed albeit slowly [8]. It has been reported that Co atom preferentially occupy $\mathrm{Cu}(1)$ [9]. While Liu et al [10] confirm that the Co atoms locate primarily at the $\mathrm{Cu}(1)$ sites at low doping level; upon increasing the $\mathrm{Co}$ concentration, some of the $\mathrm{Cu}(2)$ sites become occupied. $\mathrm{YBa}_{2}\left(\mathrm{Cu}_{1-\mathrm{x}} \mathrm{Co}_{\mathrm{x}}\right)_{3} \mathrm{O}_{7-\delta}$ has been widely investigated as a normal layer in superconductor-normal-superconductor (SNS) Josephson junctions [11].

As a contribution in this field of research the present paper deals with the study of the effect of doping with low content of cobalt, on structural and electrical properties of $\mathrm{YBa}_{2} \mathrm{Cu}_{3} \mathrm{O}_{7-\delta}$ ceramic.

\section{Experimental}

The composition $\mathrm{YBa}_{2}\left(\mathrm{Cu}_{1-\mathrm{x}} \mathrm{Co}_{\mathrm{x}}\right)_{3} \mathrm{O}_{7-\delta}$ with $\mathrm{x}=0 \%, 2 \%, 4 \%$ and $6 \%$, were prepared by solid state reaction. The oxides $\mathrm{Y}_{2} \mathrm{O}_{3}, \mathrm{CuO}$, and $\mathrm{CoO}$, carbonate $\mathrm{BaCO}_{3}$ (with a purity of $99.9 \%$ ), were ground for $1 \mathrm{~h}$ and heated to $940^{\circ} \mathrm{C}$ for $24 \mathrm{~h}$ in air. The calcined mixtures were dry-ground for $1 \mathrm{~h}$ pelletised to $13 \mathrm{~mm}$ diameter disks with 2 to $3 \mathrm{~mm}$ thick, with pressure 2 tonn $/ \mathrm{cm}^{2}$ and heated to $940^{\circ} \mathrm{C}$ for 24 $\mathrm{h}$ in air. In the present paper we study the impact of the substitution of $\mathrm{Co}^{2+}$ impurity on the transport properties of YBCO superconductor. The crystalline structures of our samples were identified by X-ray diffraction (XRD). We have measured the resistivity of several Co substituted YBCO samples as a function of temperature, by the standard four-probe technique, for studying the modifications of the transport properties. SETARAM92 differential thermal analyser (DTA) was employed to study how the mixed powders react to investigate the sinterability of the powders mixtures, the samples were heated to $980^{\circ} \mathrm{C}$ in air then the samples were cooling to room temperature a rate of it approximately of 
$5^{\circ} \mathrm{C} / \mathrm{min}$. The grain morphology of the samples was analyzed by scanning electron microscope (model JSM-6480 LV,make JEOL).

\section{Results}

\subsection{XRD Characterization}

The structural analysis of all samples has been done by using X-ray diffraction (XRD) peaks. The XRD patterns have been shown in Figure 1. The undoped sample shows all peaks corresponding to the orthorhombic phase. They are attributed to $\mathrm{YBa}_{2} \mathrm{Cu}_{3} \mathrm{O}_{7-\delta}$ phase as compared to JCPDS 82-2471 file. Appearance of peaks (003), (004), (005) and (006) in the XRD pattern with high intensity compared to other peaks, reveal the presence of certain degree of (00l) orientation of YBCO. This is may be due to stress induced by thermal cycle, or to the pelletization procedure of powders. The diffraction lines of doped samples, with $\mathrm{x}=2 \% ; 0.04 \%$ and $6 \% \mathrm{Co}$, are shifted to higher $2 \theta$ values which may be due to the stress of first order. The peak intensities for YBCO structure are affected by Co doping, where the intensities of the planes are larger for the pure sample as compared with the doped samples, but as the content of Cobalt is further increased from $x=2 \%$ to $6 \%$ the intensities of $(00 I)$ peaks began to increase together
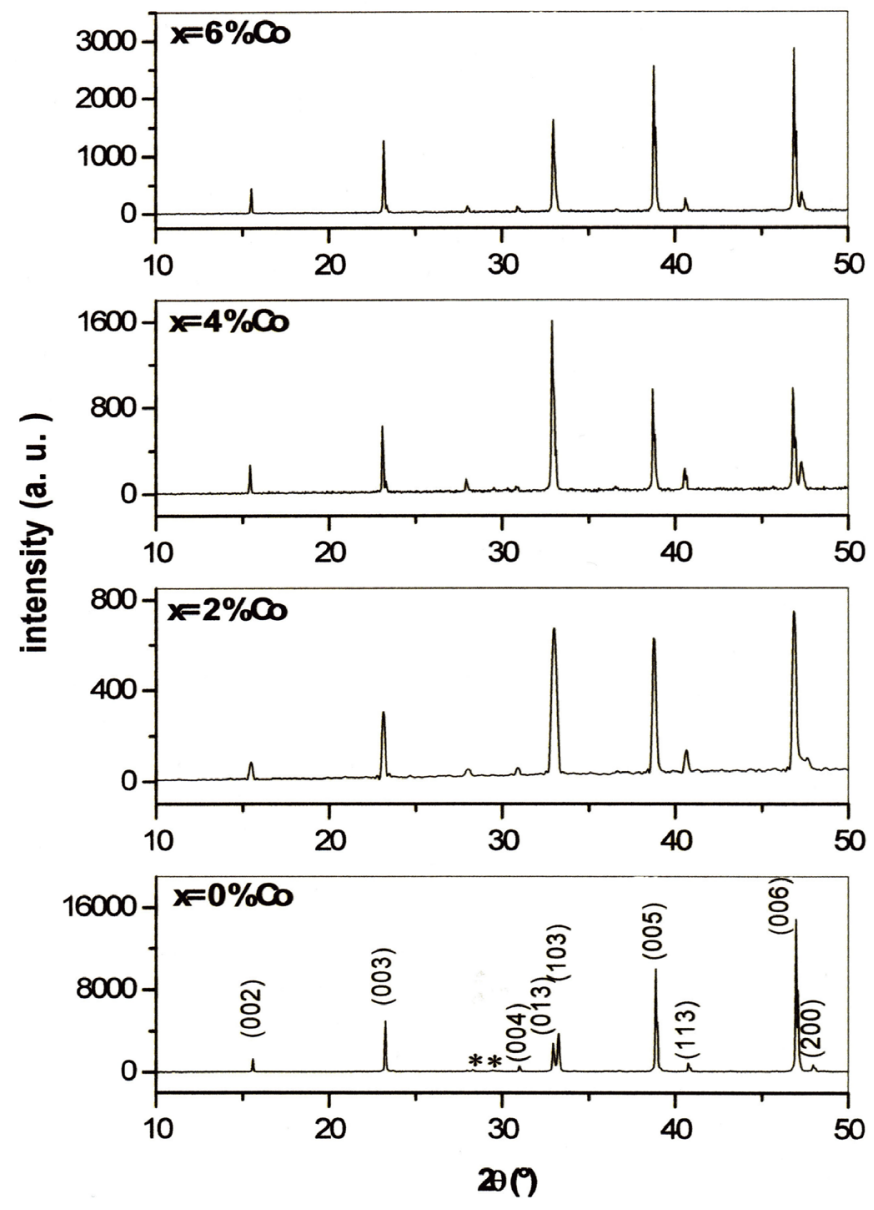

Figure 1. X-ray spectra of $\mathrm{YBa}_{2} \mathrm{Cu}_{3} \mathrm{O}_{7-\delta}$ samples doped with cobalt. 


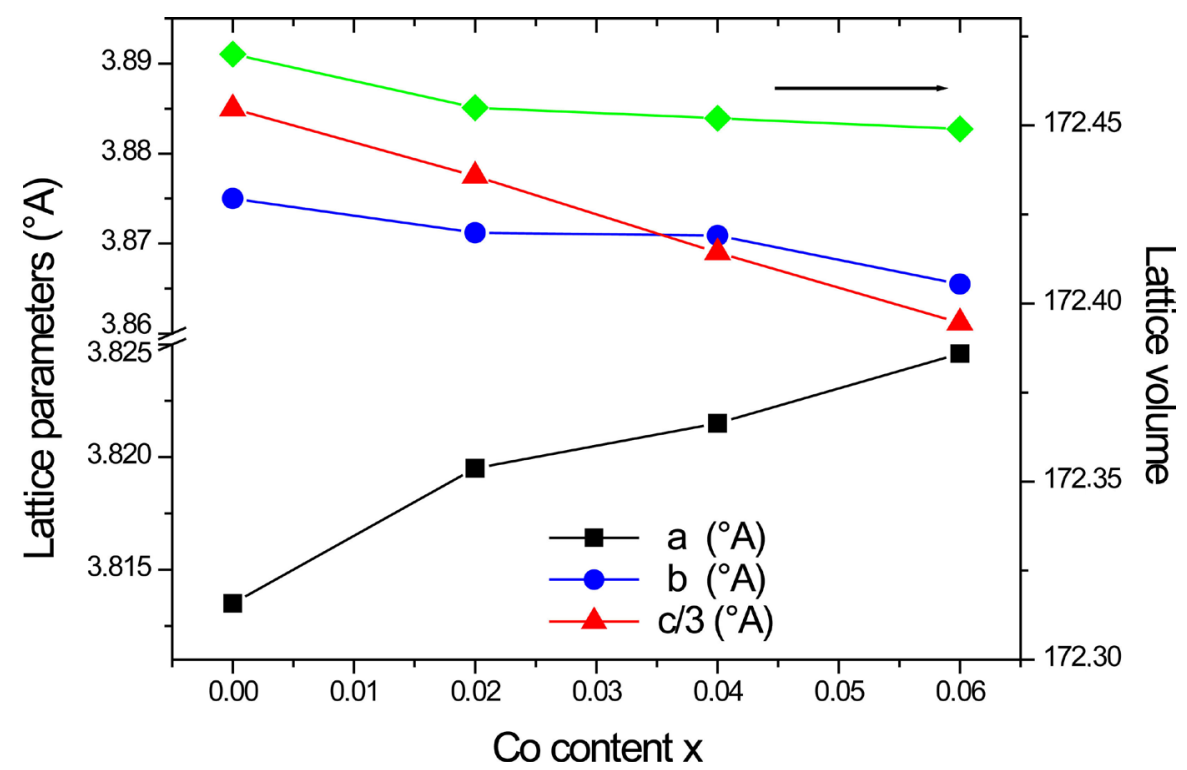

Figure 2. Lattice parameters $\mathrm{a}, \mathrm{b}$ and $\mathrm{c}$ as function of cobalt content $\mathrm{x}$ in $\mathrm{YBa}_{2}\left(\mathrm{Cu}_{1-\mathrm{x}} \mathrm{Co}_{\mathrm{x}}\right)_{3} \mathrm{O}_{7-\delta}$

with the disappearance of peaks corresponding to nonsuperconducting phase such as $\mathrm{BaCuO}_{2}$ (011). The XRD analysis allows to confirm that no impurity phase containing Cobalt is detected in any sample which confirm that the solubility limit is higher that 6 at.\% of Cobalt. As is well known, the full width at half maximum (FWHM) reflects the crystalline quality of the studied samples. The Figure 2 shows the variation of full width half maximum (FWHM) (00I) peaks as function of Co content. The FWHMs of doped samples are found greater than the pure one. This indicates the existence of defaults in the (00I) direction [12], and confirms that the grain size of the doped sample is larger than the pure one.

The Lattice parameters a, b and c, and the cell volume $\mathrm{V}$, obtained from X-ray diffraction of $\mathrm{YBa}_{2}\left(\mathrm{Cu}_{1-\mathrm{x}} \mathrm{Co}_{\mathrm{x}}\right)_{3} \mathrm{O}_{7-\delta}$ are plotted in Figure 2 as function of Cobalt content $\mathrm{x}$. The $\mathrm{b}$ and $\mathrm{c}$ parameters are found to decrease continuously while the a parameter increases with increasing $\mathrm{x}$. The unit cell volume decreases sharply with the increase of Co content. The decreasing of $c$ parameter confirms the shift of the lines to higher $2 \theta$ values as obtained in XRD patterns. The contraction of the crystallographic $c$ axis as suggested in [13] [14] could be attributed to the difference in the size of the $\mathrm{Co}^{2+}$ and $\mathrm{Cu}^{2+}$ ions $\left(r_{\mathrm{C}^{2+}}=0.65 \AA\right.$ and $\left.r_{\mathrm{Cu}^{2+}}=0.73 \AA\right)$ [15], to the loss of oxygen which is known to affect the $c$ parameter [16] and can be linked to the reduction in the local Jahn-Teller distortion of the oxygen octahedron around $\mathrm{Cu}^{2+}$. In cuprate oxides, the Jahn-Teller mode mainly corresponds to an orthorhombic distortion of $\mathrm{CuO}_{2}$ square in which two $\mathrm{Cu}-\mathrm{O}$ bonds are elongated and other two shortened [17].

The orthorhombicity $(b-a) /(b+a)$ seems to be dependent of the Co concentration (Figure 3), because it decreases with $\mathrm{x}$. There are tendency to orthorhombic/ tetragonal transition $(\mathrm{O} / \mathrm{T})$ for $\mathrm{x}>0.06$, it has found that this transition was observed when $\mathrm{x}>0.03$ for S. Elizabeth et al [18], and between $\mathrm{x}=0.12-0.15$ for liu et al [10]. 


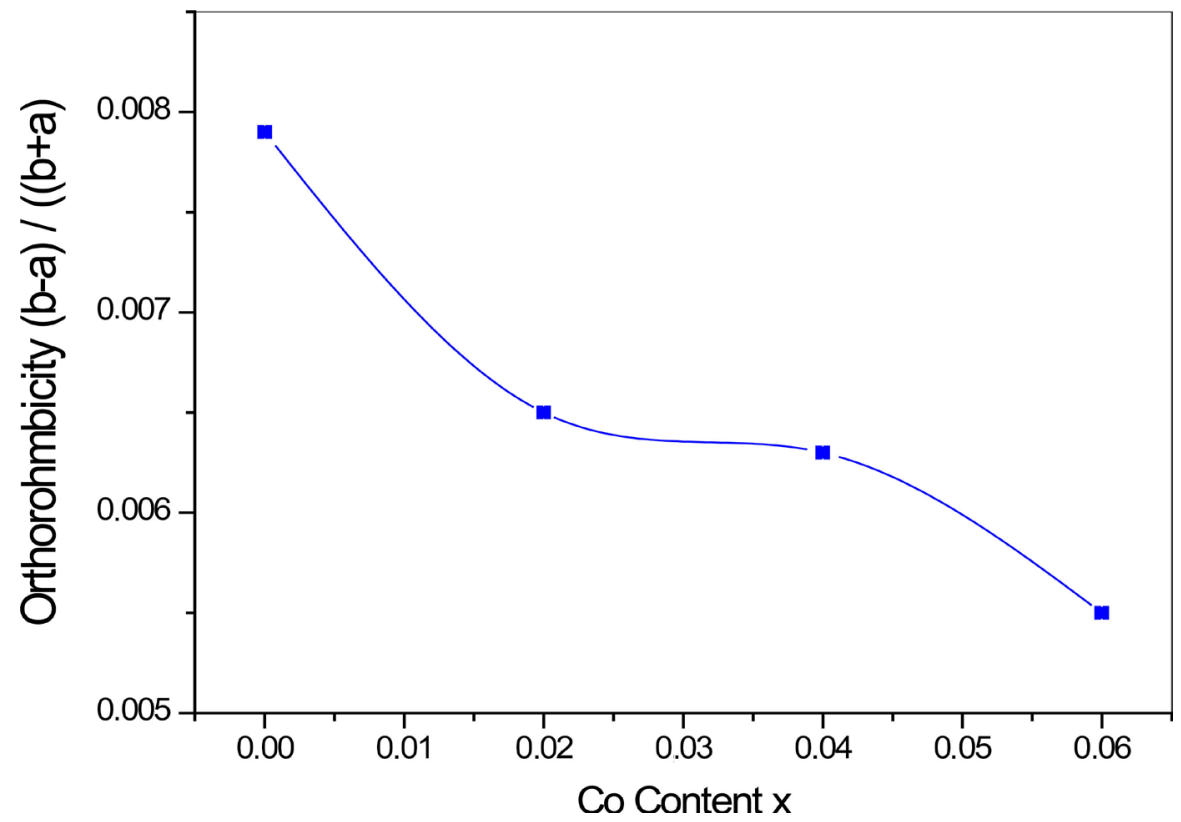

Figure 3. Variation of the orthorhombicity $(b-a) /(b+a)$ as function of Co content in $\mathrm{YBa}_{2}\left(\mathrm{Cu}_{1-\mathrm{x}} \mathrm{Co}_{\mathrm{x}}\right)_{3} \mathrm{O}_{7-\delta}$.

\subsection{Surface Microstructure}

Figure 4 shows the SEM micrographs of YBCO samples doped with 0\%, 2\% and $4 \%$ Co. the microstructure of those samples exhibits a granular structure with a dominant YBCO phase. It shows that pristine YBCO sample exhibits elongated grains randomly oriented in all directions with size varying from 5 to $20 \mu \mathrm{m}$ in length. It can be seen that microstructure of the doped sample with $x=2 \% \mathrm{Co}$, presents an identical granular structure; but with a big grain size, compared to the case of undoped sample. The micrograph of YBCO sample doped with $\% 4$ Co shows the presence of a higher porosity and very small grain sizes. Also, it is easy to observe bright grains that the amount decreases with Co content. It is suggested that these grains correspond to the presence of the nonsuperconducting $\mathrm{BaCuO}_{2}$ (011) phase, this result is in agreement with that obtained by XRD analysis, and other reported in [19] [20].

\subsection{DTA Analysis}

Figure 5 shows the DTA curves of the mixed powders. It can be seen that two endothermic peaks are observed in the DTA traces of the powders during heating. For undoped mixed powders, at about $823^{\circ} \mathrm{C}$ and $975^{\circ} \mathrm{C}$, resulting from decomposition of $\mathrm{BaCO}_{3}$ and partial melting of $\mathrm{YBa}_{2} \mathrm{Cu}_{3} \mathrm{O}_{7-\delta}$ respectively, as reported earlier [21]. In the thermograms of mixed starting powders corresponding to Co doped samples with $\mathrm{x}=0.02,0.04$, the endothermic peaks unregistered at higher temperature are found to shift to lower values of temperature. Indeed, a shift of approximatively $30^{\circ} \mathrm{C}$ is noted for the sample corresponding to $\mathrm{x}=0.02$ $\mathrm{Co}, 24^{\circ} \mathrm{C}$ for the sample with $\mathrm{x}=0.04 \mathrm{Co}$. The peak corresponding to the decomposition of $\mathrm{BaCO}_{3}$ seems to shift to higher values of temperature with $3^{\circ} \mathrm{C}$ 

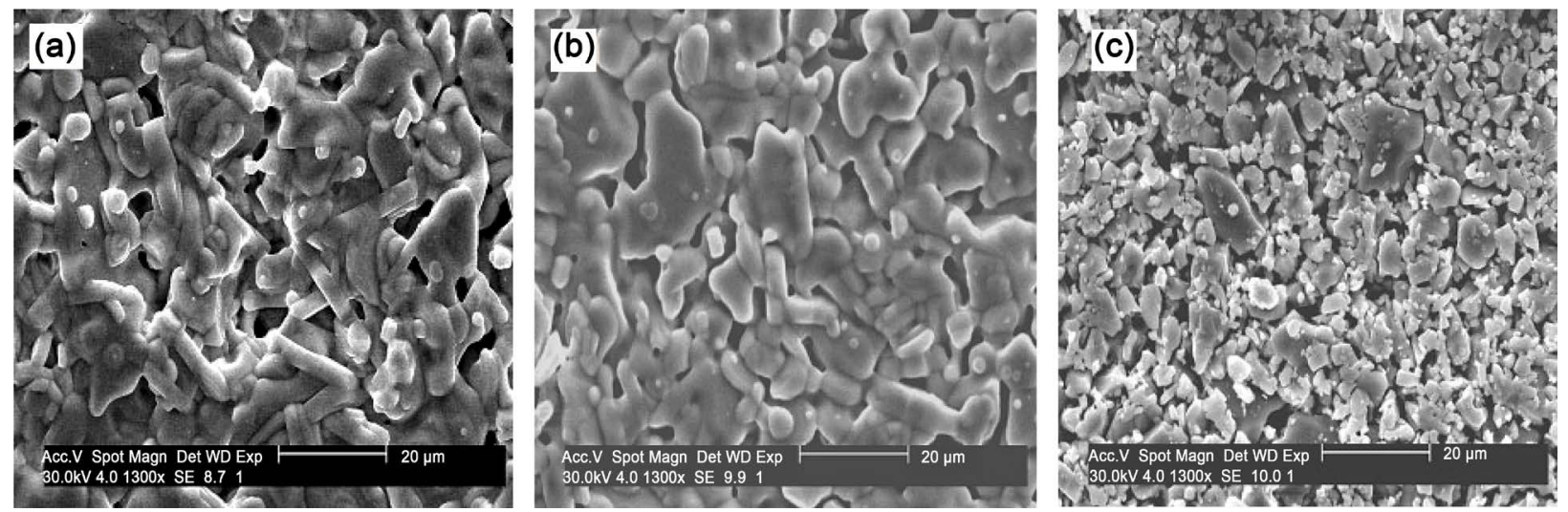

Figure 4. Micrographs of YBCO samples doped with: (a) 0\% (b) $2 \%$ and (c) 4\% Co.

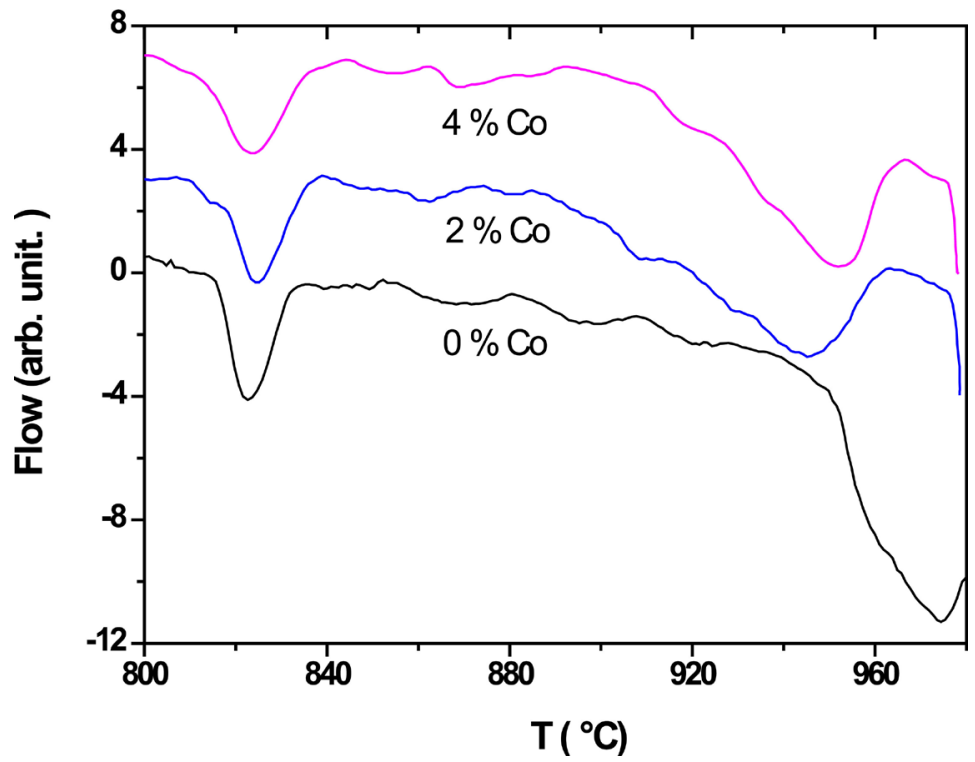

Figure 5. DTA traces for Co doped $\mathrm{YBa}_{2}\left(\mathrm{Cu}_{1-\mathrm{x}} \mathrm{Co}_{\mathrm{x}}\right)_{3} \mathrm{O}_{7-\delta}$ samples.

for $0.02 \mathrm{Co}$ and $2^{\circ} \mathrm{C}$ for $0.04 \mathrm{Co}$. This effect is also observed in the YBCO (Ag) system and $\mathrm{YBCO}(\mathrm{Zn})[22]$.

\subsection{Electrical Resistivity}

Measurements of different samples with various amounts of Cobalt are shown in Figure 6. As it can be seen from this figure, the resistivity of $\mathrm{YBa}_{2}\left(\mathrm{Cu}_{1-\mathrm{x}} \mathrm{Co}_{\mathrm{x}}\right)_{3} \mathrm{O}_{7-\delta}$ samples vs. temperature shows that for the onset transition temperature is $\mathrm{T}_{\mathrm{c}}$ onset $\sim 88^{\circ} \mathrm{K}, 82^{\circ} \mathrm{K}, 81^{\circ} \mathrm{K}$ and $80^{\circ} \mathrm{K}$ for $\mathrm{x}=0,0.002,0.004$ and 0.006 Co respectively. Decrease in the number of hole carriers by impurity doping to the $\mathrm{CuO}$ chain should be responsible for reduced Tc of YBCO phase Cobalt doping, this reduction has been estimated to $2-8 \mathrm{~K} / \mathrm{at} \%$ for trivalent dopants (M: Fe, Co and $\mathrm{Al}$ ) [23]. All samples show metallic behavior in the normal state, with high resistivity comparing to undoped sample. The residual resistivity $\left(\rho_{0}\right)$ is found by linear extrapolation of the resistivity curve in the range from $2 \mathrm{~T}_{c}$ up to room temperature. 


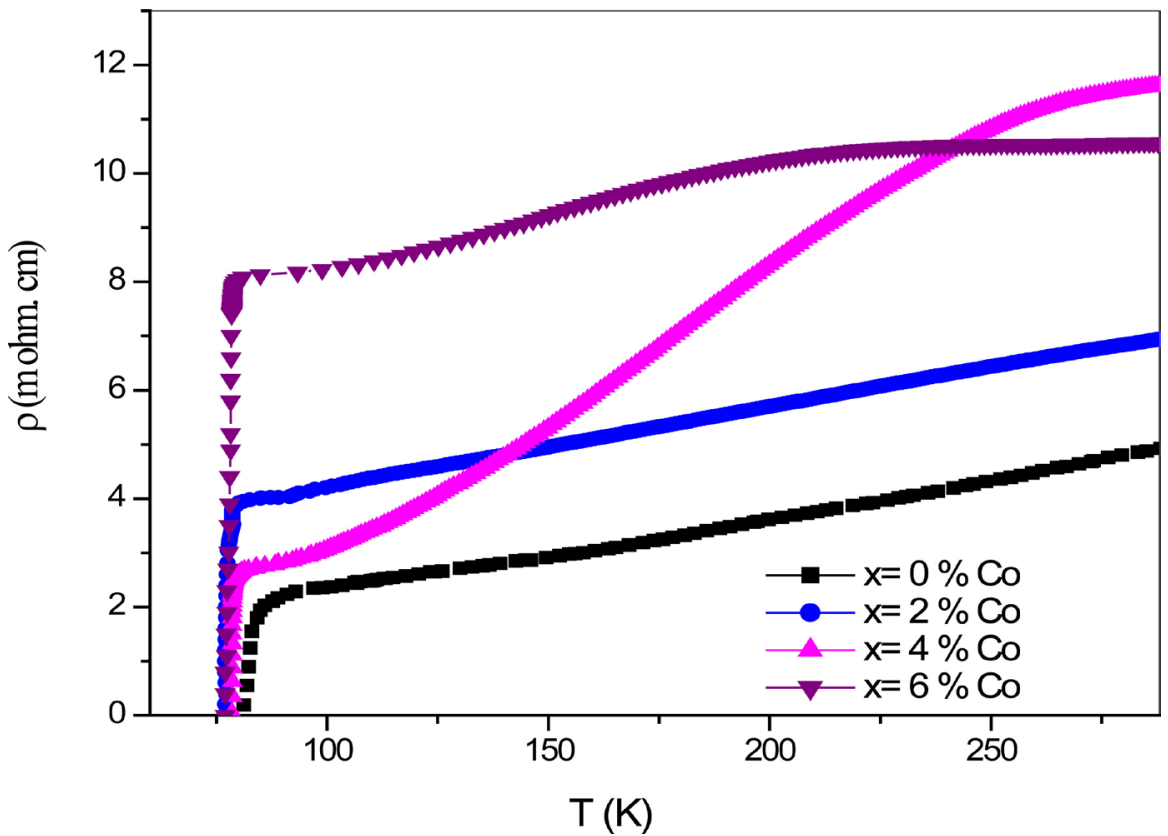

Figure 6. Variation of the resistivity as function of Co content in $\mathrm{YBa}_{2}\left(\mathrm{Cu}_{1-\mathrm{x}} \mathrm{Co}_{\mathrm{x}}\right)_{3} \mathrm{O}_{7-\delta}$.

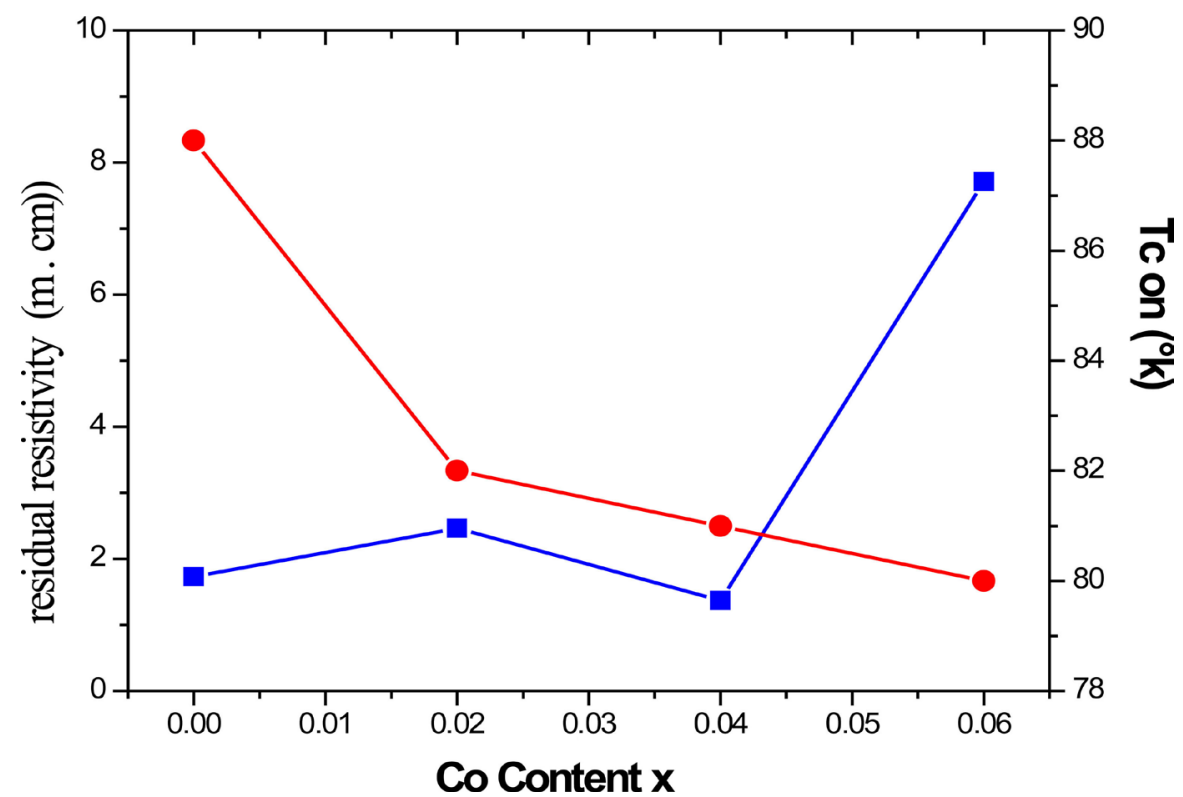

Figure 7. The onset of superconducting transition temperature Tco and residual resistivity variation $\rho_{0}$ as function of Co content in $\mathrm{YBa}_{2}\left(\mathrm{Cu}_{1-\mathrm{x}} \mathrm{Co}_{\mathrm{x}}\right)_{3} \mathrm{O}_{7-\delta}$.

As an inherent property of conducting materials, $\rho_{0}$ is modified progressively with the added composites (Figure 7). This signifies that inter granular connectivity is also modified by these composites. The residual resistivity is considered as an indicator of the sample homogeneity and defects density. The higher residual resistivity value corresponding to the sample doped with $\mathrm{x}=0.06$, these results are confirmed by the porous structure obtained in the micrographs analysis. Co doping makes the temperature dependence of the resistivity $\rho(\mathrm{T})$ deviate from linear behavior at T, especially for the sample doped with $\mathrm{x}=0.04$ 
and $\mathrm{x}=0.06$. This deviation is related to the opening of a pseudogap. As discussed for oxygen depleting crystals [24].

\section{Conclusion}

The effect of Cobalt doping on the microstructure and the normal state transport properties of polycrystalline YBCO was studied. Samples have been elaborated by the solid state reaction method and characterized by means of XRD, SEM, DTA and resistivity measurements. The crystal lattice parameters are found to change due to the cobalt doping and tendency to a structure phase transition from orthorhombic to tetragonal, which is confirmed by the decrease of the degree of orthorhombicity $(b-a) /(b+a)$. The variation of full width half maximum (FWHM) of (001) peaks as function of Co content reveals that there is a microstructural disorder caused by the cobalt incorporation. The thermal analysis of our samples reveals that the YBCO decomposition temperature is greatly lowered. In addition, the morphology examination with SEM revealed gradual increases of grain size with $\mathrm{x}=0.02 \mathrm{Co}$; a high porosity is observed in the doped samples compared to the undoped. The resistivity measurements show a deviation from linearity of $\rho(\mathrm{T})$, it is due to the opening of a pseudogap in Co doped samples.

\section{References}

[1] Yilmaz, M. and Dogan, O. (2011) Structural and Electrical Properties of Niobium Doped Y0.6Gd0.4Ba2-xNbxCu3O7-y Superconductors. Materials Sciences and Application, 2, 1090-1096.

https://www.scirp.org/Journal/PaperInformation.aspx?PaperID=6720 https://doi.org/10.4236/msa.2011.28147

[2] Maeno, Y., Kato, M., Aoki, Y., Nojima, T. and Fujita. T. (1987) Superconductivity in Modified Systems Based on $\mathrm{YBa}_{2} \mathrm{Cu}_{3} \mathrm{O}_{7-\delta}$. Physica $B+C$, 148, 357-359. http://www.sciencedirect.com/science/article/pii/0378436387902336 https://doi.org/10.1016/0378-4363(87)90233-6

[3] Ben Azzouz, F., Zouaoui, M., Mani, K.D., Annabi, M., Tendeloo, G.V. and Ben Salem, M. (2006) Structure, Microstructure and Transport Properties of B-Doped YBCO System. Physica $C, 442,13-19$.

http://www.sciencedirect.com/science/article/pii/S0921453406002656 https://doi.org/10.1016/j.physc.2006.03.135

[4] Zhang, L., Sun, X.F., Chen, X. and Zhang, H. (2003) Different Effects of Zn and Pr Doping on YBa2Cu3O7- $\delta$ - $\delta$. Physica $C$, 386, 271-274. http://www.sciencedirect.com/science/article/pii/S0921453402021251 https://doi.org/10.1016/S0921-4534(02)02125-1

[5] Liu, Y.H., Che, G.C., Li, K.Q., Zhao, Z.X., Kou, Z.Q., Di, N.L. and Cheng, Z.H. (2005) The Influence of Local Structure on Superconductivity in $\mathrm{Fe}_{0.5} \mathrm{Cu}_{0.5} \mathrm{Ba}_{2} \mathrm{YCu}_{2} \mathrm{O}$.41: A Mössbauer Effect Study. Physica C, 418, 63-67.

http://www.sciencedirect.com/science/article/pii/S0921453404013413 https://doi.org/10.1016/j.physc.2004.11.002

[6] Giri, R., Awana, V.P.S., Singh, H.K., Tiwari, R.S., Srivastava, O.N., Gupta, A., Kumaraswamy, B.V. and Kishan, H. (2005) Effect of Ca Doping for Y on Struc- 
tural/Micristructural and Superconducting Properties of YB2Cu3O7- $\delta$. Physica $C$, 419, 101-108. http://www.sciencedirect.com/science/article/pii/S0921453405000146 https://doi.org/10.1016/j.physc.2005.01.002

[7] Wang, P., Li, J., Peng, W., Chu, H.F., Li, S. and Zheng, D.N. (2007) Growth of $\mathrm{YBa}_{2} \mathrm{Cu}_{3} \mathrm{O}_{7-\delta}$ and $\mathrm{La}_{0.67} \mathrm{Ca}_{0.33} \mathrm{MnO}_{3}$ Thin Films on Silicon-on-Insulator Substrates. Physica C, 460-462, 1367-1368.

http://www.sciencedirect.com/science/article/pii/S0921453407005023

https://doi.org/10.1016/j.physc.2007.04.128

[8] Singhal, R.K. (2010) How the Substitution of $\mathrm{Zn}$ for Cu Destroys Superconductivity in YBCO System? Journal of Alloys and Compounds, 495, 1-6.

http://www.sciencedirect.com/science/article/pii/S0925838810001398 https://doi.org/10.1016/j.jallcom.2010.01.106

[9] Murugesan, M., Obara, H., Sawa, A., Kosaka, S., Nakagawa, Y., Nie, J.C. and Yamasaki, H. (2003) Microwave Surface Resistance of under Doped Co Substituted YBCO Films. Physica C, 400, 65-70.

http://www.sciencedirect.com/science/article/pii/S0921453403013297 https://doi.org/10.1016/S0921-4534(03)01329-7

[10] Liu, L., Dong, C., Zhang, J. and Li, J. (2002) The Microstructure Study of Co-Doped YBCO System. Physica $C$, 377, 348-356.

http://www.sciencedirect.com/science/article/pii/S0921453401012862 https://doi.org/10.1016/S0921-4534(01)01286-2

[11] Sydow, J.P. and Buhrman, R.A. (1999) Effect of Ozone Anneals on $\mathrm{YBa}_{2} \mathrm{Cu}_{3-\mathrm{x}} \mathrm{CoxO}_{\mathrm{z}}$ in Films. IEEE Transactions on Aplied Superconductivity, 9, 1994-1997. http://ieeexplore.ieee.org/document/784854/?section=abstract

[12] Pignon, B., Autret-Lambert, C., Ruyter, A., Decourt, R., Bassat, J.M., Monot-Laffez, I. and Ammor, L. (2008) Study of the Yttrium and Zinc Substitutions Effects in $\mathrm{Bi}_{2} \mathrm{Sr}_{2} \mathrm{CaCu}_{2} \mathrm{O}_{8+\delta}$ Compounds by Transport Measurements. Physica $C, 468,865$.

http://www.sciencedirect.com/science/article/pii/S0921453407013056 https://doi.org/10.1016/j.physc.2007.09.014

[13] Xiao, G., Bakhshai, A., Cieplak, M.Z., Tesanovic, Z. and Chien, C.L. (1989) Correlation between Superconductivity and Normal-State Properties in the $\mathrm{La}_{1.85} \mathrm{Sr}_{0.15}\left(\mathrm{Cu}_{1-\mathrm{x}} \mathrm{Zn}_{\mathrm{x}}\right) \mathrm{O}_{4}$ System. Physical Review B, 39, 315-321. https://journals.aps.org/prb/abstract/10.1103/PhysRevB.39.315 https://doi.org/10.1103/PhysRevB.39.315

[14] Raffo, L., Caciuffo, R., Rinaldi, D. and Licci, F. (1995) Effects of Mg Doping on the Superconducting Properties of $\mathrm{YBa}_{2} \mathrm{Cu}_{3} \mathrm{O}_{7 \text {-delta }}$ and $\mathrm{La}_{1.85} \mathrm{Sr}_{0.15} \mathrm{CuO}_{4}$ Systems. Superconductor Science and Technology, 8, 409.

http://iopscience.iop.org/article/10.1088/0953-2048/8/6/003/pdf https://doi.org/10.1088/0953-2048/8/6/003

[15] Tonneau, J. (2000) Table de chimie, Edition de Boeck université., Belgique. https://www.decitre.fr/livres/tables-de-chimie-9782804133016.html

[16] Attaf, S., Mosbah, M.F., Fittipaldi, R., Zola, D., Pace, S. and Vecchione, A. (2012) Effect of Double Substitution on Structural and Magnetic Properties of $\mathrm{Y}_{1-\mathrm{x}} \mathrm{Ca}_{\mathrm{x}} \mathrm{Ba}_{2}\left(\mathrm{Cu}_{1-\mathrm{y}} \mathrm{Mg}_{\mathrm{y}}\right)_{3} \mathrm{O}_{7-\delta}$. Physica C, 477, 36-42.

http://www.sciencedirect.com/science/article/pii/S0921453412000731 https://doi.org/10.1016/j.physc.2012.02.031

[17] Xue, R., Dau, H., Chen, Z., Li, T. and Xue, Y. (2013) Effects of Zn Doping on Crystal Structure, Raman Spectra and Superconductivity of $\mathrm{SmBa}_{2} \mathrm{Cu}_{3} \mathrm{O}_{7-\delta}$ Systems. Materials Science and Engineering B, 178, 363-367. 
http://www.sciencedirect.com/science/article/pii/S0921510713000172 https://doi.org/10.1016/j.mseb.2013.01.004

[18] Elizabeth, S., Anand, A., Bhat, S.V., Subramanyam, S.V. and Bhat, H.L. (1999) Influence of Cobalt Doping on Superconducting Transition in As-Grown YBCO Single Crystals. Solid State Communications, 109, 333-338. http://www.sciencedirect.com/science/article/pii/S0038109898005535 https://doi.org/10.1016/S0038-1098(98)00553-5

[19] Chuang, F.Y., Sue, D.J. and Sun, C.Y. (1995) Effects of Silver Doping on the Superconducting $\mathrm{YBa}_{2} \mathrm{Cu}_{3} \mathrm{O}_{7-\delta}$. Materials Research Bulletin, 30, 1309-1317. http://www.sciencedirect.com/science/article/pii/0025540895001107 https://doi.org/10.1016/0025-5408(95)00110-7

[20] Chamekh, S., Bouabellou, A., Elerman, Y., Kaya, M. and Dincer, I. (2017) Effects of Nickel Substitution on Crystalline Structure and Superconducting Properties of $\mathrm{YBa}_{2} \mathrm{Cu}_{3} \mathrm{O}_{7-\delta}$ Ceramics. Journal of New Technology and Materials, 7, 22-29. https://docs.google.com/viewer?a=v\&pid=sites\&srcid=ZGVmYXVsdGRvbWFpbnx qbnRtam91cm5hbHxneDo1ZWE2Mzk0ODM2ZjIyOWVk

[21] Tiagi, A.K., Tiagi, S. and Sharma, T.P. (1997) About the Substitution for $\mathrm{CuO}$ in YBCO High Temperature Superconductors. Materials Science and Engineering, 45, 88-97. http://www.sciencedirect.com/science/article/pii/S0921510796019125 https://doi.org/10.1016/S0921-5107(96)01912-5

[22] Suxiang, H. and Yanli, Z. (2004) The Anomalies of Transport Properties Due to the Normal-State Pseudogap in Co and $\mathrm{Zn}$ Doped $\mathrm{YBa}_{2} \mathrm{Cu}_{3} \mathrm{O}_{6+\delta}$ This Films. Superconductor Science and Technology, 17, 833-837.

http://iopscience.iop.org/article/10.1088/0953-2048/17/7/003/meta https://doi.org/10.1088/0953-2048/17/7/003

[23] Mahtali, M., Chamekh, S., Boucherka, T. and Bouabellou, A. (2006) Effects of Zn Doping on YBaCuO Superconductor. Physica Status Solidi, 9, 3040-3043. http://onlinelibrary.wiley.com/doi/10.1002/pssc.200567137/abstract https://doi.org/10.1002/pssc.200567137

[24] Yao, X., Oka, A., Izumi, T. and Shiohar, Y. (2004) Crystal Growth and Superconductivity of Fe-Doped YBCO Single Crystals. Physica C: Superconductivity, 339, 99-105. http://www.sciencedirect.com/science/article/pii/S0921453400003336 